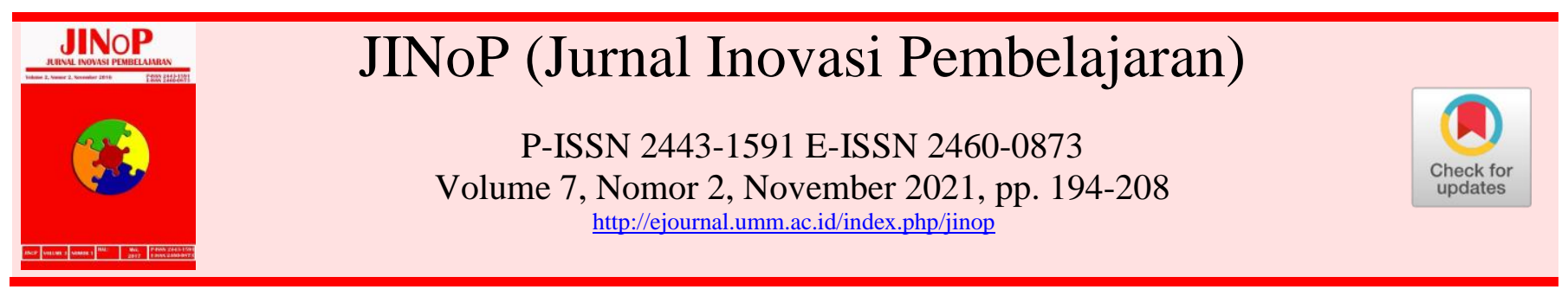

\title{
Pengembangan gim kuis edukasi suplemen buku ajar pengantar dasar IPA berbasis website
}

\author{
Rohmani $^{1 *}$, Berta Apriza $^{2)}$, Yasinta Mahendra ${ }^{3)}$ \\ ${ }^{1}$ Program Studi Pendidikan Guru Sekolah dasar, Fakultas Keguruan dan Ilmu Pendidikan, \\ Universitas Muhammadiyah Kotabumi, Jl. Hasan Kepala Ratu Sindangsari, Kotabumi, Indonesia \\ ${ }^{2}$ Program Studi Pendidikan Guru Sekolah dasar, Fakultas Keguruan dan Ilmu Pendidikan, \\ Universitas Muhammadiyah Kotabumi, Jl. Hasan Kepala Ratu Sindangsari, Kotabumi, Indonesia \\ ${ }^{3}$ Program Studi Pendidikan Guru Sekolah dasar, Fakultas Keguruan dan Ilmu Pendidikan, \\ Universitas Muhammadiyah Kotabumi, Jl. Hasan Kepala Ratu Sindangsari, Kotabumi, Indonesia
}

rohman.orgos@gmail.com *; berta.apriza@umko.ac.id ; yasinta.mahendra2014@gmail.com *Penulis Koresponden

\begin{abstract}
ABSTRAK
Perkembangan teknologi di era digital menuntut adanya inovasi dalam pembelajaran. Inovasi pembelajaran berkembang sesuai kebutuhan dan tuntutan penyelesaian masalah di lapangan. Penelitian ini bertujuan untuk mengembangkan suplemen buku ajar pengantar dasar IPA dalam bentuk gim kuis berbasis website yang dapat diakses menggunakan ponsel pintar. Gim kuis suplemen buku ajar dibuat dengan tujuan untuk memaksimalkan pemanfaatan ponsel pintar yang dimiliki mahasiswa dan mengurangi berbagai dampak negatif penggunaan ponsel pintar dalam pembelajaran. Metode dalam penelitian ini yaitu metode Research and Development (R\&D) menggunakan model prosedural. Instrumen pengumpulan data dalam penelitian ini berupa lembar validasi, lembar angket respons mahasiswa, dan soal tes. Subjek uji coba pada penelitian ini adalah 73 mahasiswa program studi Pendidikan Guru Sekolah Dasar Universitas Muhammadiyah Kotabumi. Hasil uji kelayakan gim kuis sebesar 79,42\% dan dinyatakan layak karena lebih besar dari $61 \%$. Tingkat efektivitas gim kuis sebesar 90,47\% dan dinyatakan efektif karena lebih besar dari 80\%. Uji praktis kepraktisan penggunaan gim kuis sebesar 87,06\% dinyatakan praktis karena lebih besar dari $61 \%$. Penggunaan gim kuis suplemen buku ajar pengantar dasar IPA dapat meningkatkan hasil belajar mahasiswa dan mampu mengurangi dampak negatif penggunaan ponsel pintar serta memaksimalkan manfaat penggunaan ponsel pintar dalam pembelajaran.

Kata kunci: Gim Kuis; Website; Buku Ajar; Pengantar Dasar IPA.
\end{abstract}

\section{ABSTRACT}

Technological developments in the digital era demands innovation in learning. Learning innovation is developed according to the needs and demands of solving problems in the field. This study aimed to develop a supplementary basic introductory science textbook in the form of a website-based quiz game that can be accessed using a smartphone. The textbook supplement quiz game was created with the aim of maximizing the use of smartphones owned by students and reducing the negative impacts of using smartphones in learning. The method in this study was Research and Development (R\&D) method using a procedural model. The data collection instruments in this study were validation sheets, student response questionnaire sheets, and test questions. The test subjects in this study were 73 students of the elementary school teacher education program at the Muhammadiyah University of Kotabumi. The results of the quiz game feasibility test were $79.42 \%$ and were declared eligible because they were greater than $61 \%$. The level of effectiveness of the quiz game is $90.47 \%$ and is declared effective because it is greater than $80 \%$. Practical test of the practicality of using quiz games by $87.06 \%$ was declared practical 
because it was greater than 61\%. The use of quiz games supplementing the basic introductory science textbooks can improve student learning outcomes and be able to reduce the negative impact of smartphone use and maximize the benefits of using smartphones in learning.

Keywords: Quiz Game; Websites; Textbooks; Basic Introduction to Science

diunggah: 2021/11/03, direvisi: 2021/11/09, diterima: 2021/11/14, dipublikasi: 2021/11/30

Copyright (c) 2021 Rohmani et al

This is an open access article under the CC-BY license

Cara sitasi: Rohmani, Apriza, B., \& Mahendra, Y. (2021). Pengembangan gim kuis edukasi suplemen buku ajar pengantar dasar IPA berbasis website. JINoP (Jurnal Inovasi Pembelajaran), 7(2). https://doi.org/10.22219/jinop.v7i2.18576

\section{PENDAHULUAN}

Buku ajar adalah buku yang digunakan sebagai acuan standar untuk pendidikan formal pada mata pelajaran tertentu (Alfiras \& Bojiah, 2020). Pengertian yang lebih luas berdasarkan berbagai acuan dan fakta, buku ajar adalah platform standar pengetahuan bagi peserta didik (Bierman et al., 2006). Buku ajar merupakan alat pembelajaran yang membantu dalam menjelaskan berbagai konsep dan istilah (Van Boxtel et al., 2000). Bahkan, buku ajar dapat digunakan untuk membimbing peserta didik ketika menganalisis dan memecahkan masalah (Horsley et al., 2010). Selain membantu proses belajar-mengajar, buku ajar juga dapat membantu peserta didik dalam mengembangkan potensi yang ada pada dirinya (Knight, 2015). Oleh karena itu, buku ajar sangat mempengaruhi kualitas pendidikan (Sun et al., 2012).

Memasuki era digital dengan perkembangannya yang begitu pesat, buku ajar bentuk cetak berkembang menjadi buku ajar bentuk digital yang lebih murah dan mudah diakses (Rao, 2005). Perkembangan buku ajar cetak menjadi buku ajar digital merupakan bagian dari penyesuaian terhadap perkembangan teknologi. Berbagai penyesuaian aspek lain terkait perkembangan teknologi, dibutuhkan pemahaman yang mendalam terhadap sains dan teknologi sebagai dasar pemikiran dalam pemecahan berbagai masalah di masyarakat (Al-Qaysi et al., 2020). Kemampuan penguasaan teknologi digital sangat dibutuhkan agar dapat terus dapat mengikuti setiap perkembangan zaman (McKenna, 2019; Rahman et al., 2021). Kualitas pendidikan Indonesia tidak terlepas dari peran teknologi digital, sehingga wajar jika terdapat perbedaan kualitas pendidikan di berbagai wilayah Indonesia. Daerah dengan dukungan fasilitas teknologi yang memadai, baik infrastruktur maupun perangkat teknologi dalam pembelajaran, memiliki kualitas pendidikan yang lebih baik dibandingkan dengan daerah dengan kondisi fasilitas pendukung dalam penggunaan teknologi yang belum memadai (Raymond, 2012). Era digital menjadikan ilmu pengetahuan dapat diperoleh tidak hanya di dalam kelas, tetapi dapat diperoleh di mana saja selama ada perangkat teknologi digital (Traverso et al., 2014).

Menurut Stone \& Baker-Eveleth, (2013) pesatnya perkembangan teknologi tidak dapat disangkal membawa inovasi yang dapat memainkan peran penting dalam pendidikan. Inovasi ini telah memberikan akses peserta didik ke lebih banyak informasi dari sebelum meluasnya perkembangan teknologi. Perangkat teknologi berupa ponsel pintar (smartphone) merupakan salah satu produk teknologi digital dan telah digunakan di berbagai kalangan dan usia (Csibi et al., 2019), mulai usia 3 
tahun sampai 50 tahun ke atas. Hal ini menjelaskan bahwa ponsel pintar telah dikenal oleh masyarakat secara luas.

Di Indonesia sebagian besar masyarakat (Pusparisa, 2021) sudah menggunakan ponsel pintar, yaitu sebesar 160,23 juta atau $58,6 \%$ dari total seluruh penduduk. Dilihat dari rentang usia 20-29 tahun atau usia pelajar/mahasiswa sebanyak 70,59\% telah memiliki ponsel pintar (Kominfo, 2017). Lebih spesifik lagi, data dari Kominfo menunjukkan untuk pelajar jenjang diploma/S1 sebesar 93,02\% telah memiliki ponsel pintar. Data tersebut menunjukkan pelajar di kalangan mahasiswa S1 sudah tidak asing lagi dengan ponsel pintar. Penggunaan ponsel pintar di kalangan mahasiswa cenderung lebih banyak digunakan untuk sosial media dan juga bermain game dibandingkan untuk mengakses informasi pendidikan (Csibi et al., 2019; Kominfo, 2017). Perbandingan penggunaan ponsel pintar di rumah, di kamar atau sekolah/kampus dibandingkan dengan di mana saja (Kominfo, 2017), ponsel pintar cenderung paling banyak digunakan di mana saja (tempat umum, tempat nongkrong, dan lain-lain).

Ponsel pintar jika benar-benar dimanfaatkan untuk mengakses materi-materi pelajaran akan memberikan kemudahan dan manfaat yang besar bagi mahasiswa. Akan tetapi, penggunaan ponsel pintar tidak terkontrol bahkan saat jam pelajaran di kelas (Traverso et al., 2014) mahasiswa lebih banyak bermain ponsel pintar untuk bermain gim atau mengakses sosial media sehingga tidak fokus pada pelajaran. Guna mengurangi dampak negatif dan memaksimalkan fungsi ponsel pintar dalam pembelajaran, teknologi pembelajaran berbasis gim yang dapat dimainkan menggunakan ponsel pintar menjadi alternatif pilihan yang perlu untuk dikembangkan (Abildinovaa et al., 2016).

Pembelajaran menggunakan aplikasi gim menjadikan peserta didik lebih aktif dan lebih menyenangi pelajaran tersebut (Kapralos et al., 2015). Suatu informasi atau pengetahuan akan lebih mudah diperoleh jika peserta didik menyenangi hal tersebut, begitu juga sebaliknya jika sesuatu sudah tidak disenangi maka akan sangat sulit untuk diterima dan dipahami. Keaktifan akan menjadikan peserta didik lebih baik memahami pelajaran dibandingkan dengan peserta didik yang pasif (Magoc, 2011). Banyak penelitian terkait pembelajaran menggunakan aplikasi gim (Gorbanev et al., 2018; Philpot et al., 2005; Wang, 2008) tetapi fokus penelitian mereka berbeda satu dengan yang lainnya. Philpot et al., (2005) fokus pada penggunaan gim dalam menumbuhkan kemahiran dan kepercayaan diri peserta didik. Gorbanev et al., (2018) fokus pada strategi pembelajaran menggunakan permainan medis. Sedangkan Wang (2008), fokus pada penilaian formatif menggunakan gim kuis berbasis website pilihan berganda.

Dari penelitian-penelitian yang sudah dilakukan, masih jarang yang membahas tentang penggunaan buku ajar yang diintegrasikan ke dalam sebuah gim edukasi. Buku ajar yang berkembang saat ini berupa buku ajar cetak dan juga buku ajar digital (Alfiras \& Bojiah, 2020; Mascita, 2021). Buku ajar sebagai sumber belajar bagi mahasiswa memiliki peran penting dalam kesuksesan belajar mahasiswa. Namun, perkembangan teknologi menjadikan mahasiswa lebih senang menggunakan ponsel pintar dibandingkan membaca buku ajar sehingga prestasi akademiknya menurun (Utami, 2019). Guna meningkatkan ketertarikan membaca dan memahami buku ajar baik cetak maupun digital diperlukan suplemen buku ajar yang terintegrasi ke dalam aplikasi gim yang dapat diakses menggunakan ponsel pintar. Suplemen buku ajar dalam bentuk aplikasi gim diyakini dapat meningkatkan kualitas pembelajaran dan meminimalkan dampak negatif dari 
penggunaan ponsel pintar dalam pembelajaran (Hermawan et al., 2019; Salmy et al., 2018). Guna memperoleh produk suplemen buku ajar dalam bentuk aplikasi gim, diperlukan sebuah penelitian yang lebih lanjut. Tujuan dari penelitian ini adalah untuk mengembangkan suplemen buku ajar pengantar dasar IPA dalam bentuk aplikasi gim kuis berbasis website untuk digunakan mahasiswa PGSD Universitas Muhammadiyah Kotabumi dalam perkuliahan pengantar dasar IPA.

Suplemen buku ajar pengantar dasar IPA dalam bentuk gim edukasi diyakini mampu meningkatkan hasil belajar mahasiswa. Hal ini didasarkan pada penggunaan gim dalam pembelajaran mampu menciptakan kondisi lingkungan belajar yang menyenangkan (Broussard, 2014). Selain dapat menciptakan kondisi belajar yang menyenangkan, pembelajaran menggunakan gim juga dapat meningkatkan kemampuan berpikir peserta didik (Meishar-Tal \& Kesler, 2021).

\section{METODE}

Riset ini merupakan jenis penelitian dan pengembangan yang juga disebut sebagai research and development. Pengembangan suplemen buku ajar berbentuk aplikasi gim kuis berbasis website mengadopsi langkah-langkah penelitian pengembangan Sugiyono (2016) dalam 9 tahap penelitian dan pengembangan, meliputi 1) tahap temuan potensi dan masalah; 2) tahap pengumpulan informasi; 3) tahap desain produk; 4) tahap validasi desain; 5) tahap perbaikan desain; 6) tahap uji coba desain; 7) tahap revisi desain; 8) tahap uji coba pemakaian; dan 9) tahap revisi produk akhir. Guna memperoleh produk yang layak dalam prosesnya melibatkan 2 orang validator Ahli materi, 2 orang validator ahli media dan 2 orang praktisi. Populasi dalam penelitian ini adalah mahasiswa PGSD Universitas Muhammadiyah Kotabumi dengan sampel uji coba produk dan uji coba pemakaian 87 mahasiswa.

Instrumen penelitian yang digunakan adalah lembar penilaian validasi, lembar angket respons mahasiswa, dan soal tes. Lembar penilaian validasi berupa angket untuk lima indikator dengan penilaian menggunakan skala likert. Soal tes terkait materi dalam buku ajar pengantar dasar IPA diberikan kepada subjek uji coba gim kuis. Angket respons penggunaan gim kuis berisi 2 jenis pernyataan diberikan kepada subjek uji coba. Angket respons dibuat dengan Skala Guttman berupa pernyataan positif dan pernyataan negatif. Ketiga instrumen dianalisis menggunakan teknik analisis data berupa uji kevalidan produk, uji kepraktisan produk, dan uji keefektifan produk.

Guna memperoleh produk pengembangan yang valid, gim kuis suplemen buku ajar pengantar dasar IPA dilakukan uji kevalidan. Tingkat kevalidan produk hasil pengembangan dalam bentuk persentase dengan mengacu pada tingkat apa yang disampaikan oleh Riduwan yang menyatakan bahwa suatu produk dikatakan memenuhi kriteria valid jika persentase hasil uji kevalidan lebih besar atau sama dengan 61\% (Riduwan, 2011). Adapun perhitungan persentase hasil uji kevalidan sebagai berikut.

$$
P(\%)=\frac{\sum \text { skor hasil pengumpulan data }}{\text { skor kriterium }} \times 100 \%
$$


Produk hasil pengembangan selain harus valid, juga harus praktis untuk digunakan. Untuk mengetahui tingkat kepraktisan dari produk hasil pengembangan diperlukan uji kepraktisan. Uji kepraktisan gim kuis dilakukan dengan memberikan angket kepada peserta uji coba. Gim kuis dikatakan praktis jika persentase rata-rata dari yang menjawab "Ya" diatas 61\% (Riduwan, 2011). Untuk menghitung persentase kepraktisan digunakan rumus sebagai berikut.

$$
P=\frac{\text { Jumlah Jawaban ya }}{\text { Jumlah jawaban }} \times 100 \%
$$

Selain harus valid dan juga praktis untuk digunakan, produk gim kuis juga harus efektif jika digunakan dalam pembelajaran. Gim kuis dikatakan efektif jika persentase ketuntasan klasikal (KK) peserta didik diatas 80\% (Riduwan, 2011). Keefektifan penggunaan gim kuis dalam pembelajaran dilihat dari uji t berpasangan dengan taraf kepercayaan $95 \%$ dan juga uji normalitas yang perhitungannya menggunakan aplikasi SPP. Persentase ketuntasan klasikal hasil belajar mahasiswa menggunakan gim kuis dihitung dengan persamaan sebagai berikut.

$$
K K=\frac{\sum \text { Tuntas }}{\sum \text { Tidak tuntas }} \times 100 \%
$$

\section{HASIL DAN PEMBAHASAN}

Penelitian ini menghasilkan produk berupa suplemen buku ajar pengantar dasar IPA berbentuk gim kuis berbasis website dengan 9 tahapan penelitian dan pengembangan. Berikut uraian dari 9 tahapan penelitian dan pengembangan produk gim kuis suplemen buku ajar berbasis website.

\section{Hasil tahap temuan potensi dan masalah}

Temuan potensi dan masalah dalam penelitian ini yaitu mahasiswa PGSD Universitas Muhammadiyah Kotabumi saat berada di kampus semuanya membawa ponsel pintar. Hal ini diketahui dari saat mahasiswa melakukan presensi perkuliahan di siakad dengan memindai bardcode yang diberikan dosen. Permasalahan terjadi ketika mahasiswa saat berada di lingkungan kampus bahkan saat di kelas pada jam perkuliahan, mahasiswa selalu fokus pada ponsel pintar yang ada di saku maupun di tas terutama terjadi pada mahasiswi. Perhatian mereka lebih terfokus kepada ponsel pintar untuk mengakses sosial media dan juga bermain gim dari pada membaca buku pelajaran. Kondisi seperti ini menjadi permasalahan yang harus dicarikan solusinya. Dimilikinya ponsel pintar oleh semua mahasiswa, memiliki potensi untuk adanya inovasi penerapan pembelajaran dengan memanfaatkan ponsel pintar (Stone \& Baker-Eveleth, 2013).

\section{Hasil tahap pengumpulan informasi}

Berdasarkan hasil temuan potensi dan masalah, dilakukan pengumpulan informasi lanjut terkait inovasi yang sesuai dengan penerapan pembelajaran menggunakan ponsel pintar. Penggunaan aplikasi gim yang begitu disenangi, menjadikan aplikasi gim sebagai fokus penelitian. Aplikasi gim dapat diintegrasikan ke dalam pembelajaran dan mudah diakses oleh mahasiswa yaitu aplikasi gim berbasis website (Wang, 2008). Aplikasi gim berbasis website 
memanfaatkan teknologi world wide website (www) (John, 2020) sehingga tidak menghabiskan ruang penyimpanan ponsel pintar dan dapat diakses mahasiswa selama terhubung dengan jaringan internet.

Gim berbasis website dapat dikembangkan menggunakan bahasa pemrograman PHP dan dikombinasikan dengan HTML serta CSS. Bahasa pemrogramam PHP merupakan bahasa pemrograman server side scripting yang bersifat open source (Awwaabiin, 2020). Bahasa pemrograman PHP memiliki kelebihan dapat digunakan dengan berbagai jenis database, memiliki kecepatan akses tinggi, serta dapat dikombinasikan dengan bahasa pemrograman lain. Database sebagai penyimpanan data gim yang dapat diakses menggunakan PHP salah satunya adalah MYSQL. Untuk dapat diakses menggunakan ponsel pintar, aplikasi gim kuis disimpan ke dalam hosting agar dapat diakses secara daring melalui nama domain.

\section{Hasil tahap desain produk}

Informasi yang diperoleh dari tahap sebelumnya, menjadi acuan pada tahap desain produk. Aplikasi gim kuis didesain melalui 2 tahap yaitu desain awal tampilan dalam bentuk story board, kemudian dilanjutkan ke desain fungsi dari setiap tombol atau menu yang telah dibuat. Pembuatan desain awal menggunakan aplikasi Microsoft Word, sedangkan realisasi desain ke dalam bentuk aplikasi game kuis berbasis website menggunakan aplikasi Atom text editor. Layout dan tampilan dari gim kuis hasil pengembangan dijelaskan sebagai berikut.

a. Hasil perencanaan desain layout

Hasil tahap perencanaan desain layout game kuis berupa sketsa kasar visual dari aplikasi game kuis dalam bentuk story board. Berikut visual dari layout gim kuis berbasis website.

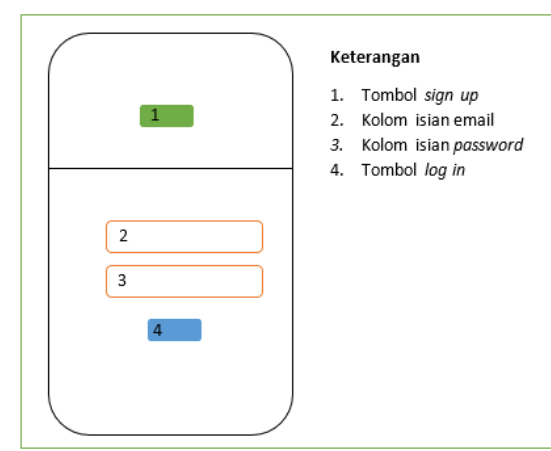

Gambar 1. Layout tampilan halaman awal

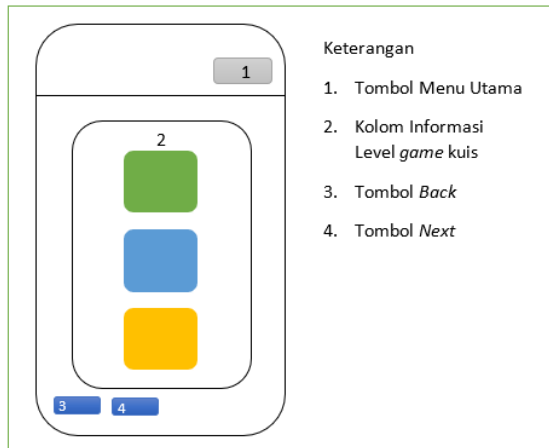

Gambar 3. Layout tampilan daftar level gim

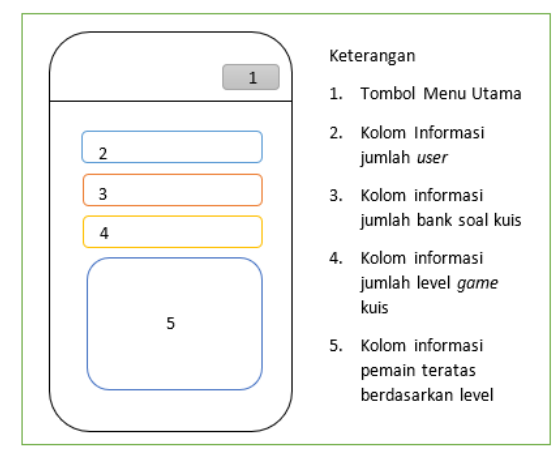

Gambar 2. Layout tampilan halaman beranda

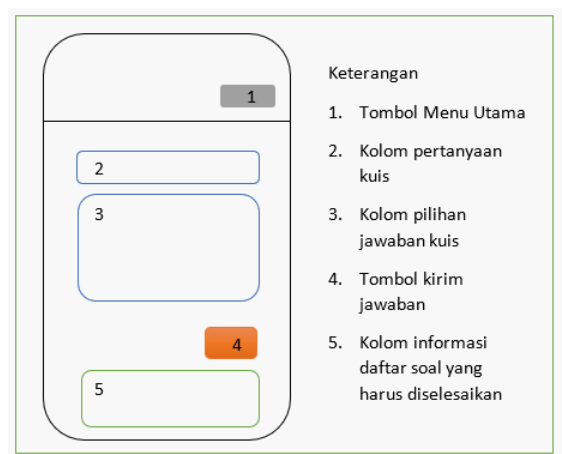

Gambar 4. Layout tampilan penyelesaian level kuis 
b. Hasil pengembangan

Berdasarkan hasil pada tahap perencanaan desain layout yang telah dibuat, kemudian direalisasikan ke dalam bentuk gim dengan beberapa penyesuaian warna, text, gambar, tombol dll. Berikut tampilan hasil pengembangan gim kuis berbasis website suplemen buku ajar pengantar dasar IPA.

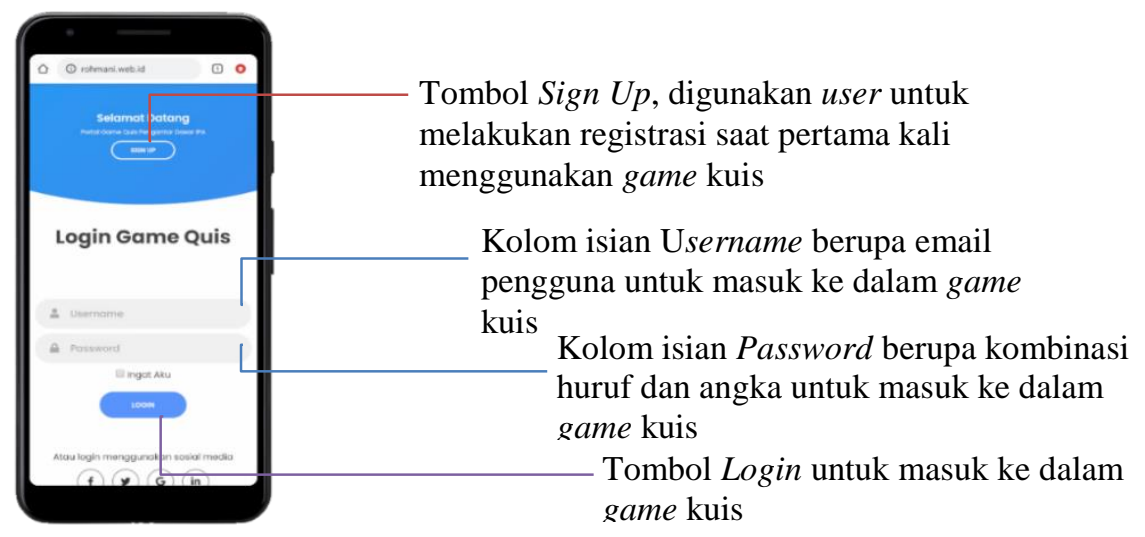

Gambar 5. Tampilan halaman awal game kuis
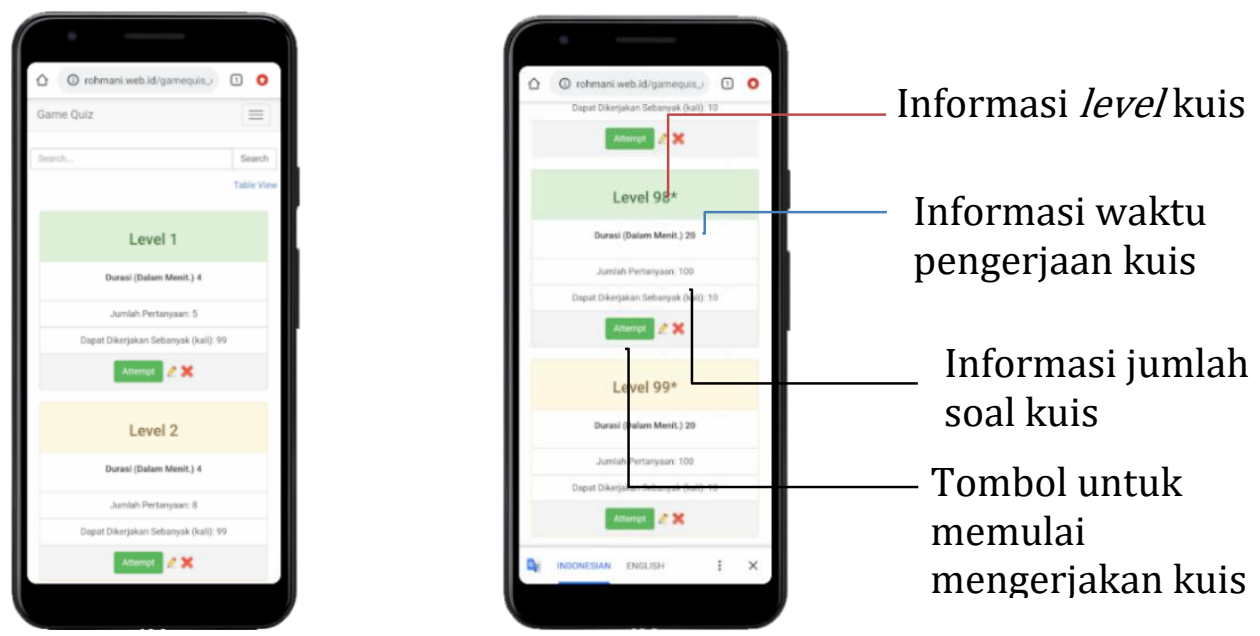

\section{Gambar 6. Tampilan halaman level game kuis}

Pada tampilan halaman level gim kuis, memuat informasi tentang level serta beberapa informasi terkait durasi waktu dan jumlah soal. Level gim kuis dibuat sebanyak 100 level dengan asumsi bahwa 1 level mewakili 1 nilai. Mahasiswa yang mampu menyelesaikan level 70 akan memperoleh nilai 70, dan jika selesai sampai level 100 akan memperoleh nilai 10. Masing-masing level memiliki tingkat kesulitan yang berbeda beda baik dari jumlah soal, maupun durasi waktu.

Setiap materi dari buku ajar pengantar dasar IPA dibuat 7 sampai 10 level, sehingga untuk mencapai level 100 mahasiswa harus sudah menguasai seluruh 
materi buku ajar pengantar dasar IPA. Level kuis didesain dengan penyelesaian soal harus benar semua setiap satu kali mengerjakan. Jika mahasiswa mengerjakan terdapat 1 atau beberapa soal yang dijawab salah maka akan mengulang dengan materi yang sama tetapi soal bisa jadi sama atau berbeda yang diambil dari bank soal secara acak.

\section{Hasil tahap validasi desain}

Hasil pengembangan gim kuis pada tahap sebelumnya, dilakukan validasi oleh beberapa validator untuk mengetahui kelayakannya. Validator yang diminta untuk memvalidasi gim kuis adalah ahli media, ahli materi dan praktisi. Berikut hasil validasi gim kuis berbasis website sebagai suplemen buku ajar pengantar dasar IPA.

a. Validasi ahli media

Gim kuis suplemen buku ajar pengantar dasar IPA hasil pengembangan dinilai dan divalidasi oleh ahli media untuk mengetahui kelayakannya. Ahli media menilai produk hasil pengembangan berdasarkan lembar validasi dengan rentang nilai 1 sampai 4. Aspek penilaian meliputi tampilan gim kuis, konten/isi gim kuis, penggunaan warna, serta interaktifitas. Berikut ringkasan hasil penilaian gim kuis buku ajar pengantar dasar IPA oleh ahli media disajikan pada tabel 1 .

Tabel 1. Hasil validasi ahli media

\begin{tabular}{lcllc}
\hline Aspek yang dinilai & $\begin{array}{l}\text { Perolehan } \\
\text { skor }\end{array}$ & $\begin{array}{l}\text { Skor } \\
\text { mak. }\end{array}$ & $\begin{array}{l}\text { Persentase } \\
\text { Skor }(\boldsymbol{\%})\end{array}$ & Keterangan \\
\hline Tampilan game kuis & 25 & 32 & 78,12 & Baik \\
$\begin{array}{l}\text { Konten/isi game kuis } \\
\text { Penggunaan warna }\end{array}$ & 12 & 16 & 75 & Baik \\
background dan konten & 10 & 12 & 83,33 & Sangat Baik \\
Interaktifitas & 13 & 16 & 81,25 & Sangat Baik \\
\hline
\end{tabular}

Rerata hasil dari validasi ahli media terhadap gim kuis suplemen buku ajar pengantar dasar IPA sebesar 79,42\%. Gim kuis ditinjau dari segi media dinyatakan valid karena rerata validasi ahli media lebih dari $61 \%$.

b. Validasi ahli materi

Gim kuis suplemen buku ajar pengantar dasar IPA selain divalidasi oleh ahli media, juga divalidasi oleh ahli materi. Aspek yang dinilai oleh validator materi berupa pembagian materi tiap level kuis, kesesuaian soal dengan pilihan, kesesuaian kuis dengan durasi waktu, serta tingkat kesulitan soal tiap level. Berikut ringkasan hasil validasi dari ahli materi (tabel 2).

Tabel 2. Validasi ahli materi

\begin{tabular}{lcccc}
\hline Aspek Penilaian & $\begin{array}{c}\text { Perolehan } \\
\text { skor }\end{array}$ & Skor Mak. & $\begin{array}{c}\text { Persentase } \\
(\mathbf{\%})\end{array}$ & Ket. \\
\hline $\begin{array}{l}\text { Pembagian materi tiap level } \\
\text { kuis }\end{array}$ & 9 & 12 & 75 & Baik \\
$\begin{array}{l}\text { Kesesuaian soal kuis dengan } \\
\text { pilihan }\end{array}$ & 8 & 12 & 88,3 & $\begin{array}{c}\text { Sangat } \\
\text { Baik }\end{array}$
\end{tabular}




$\begin{array}{lcccc}\begin{array}{l}\text { Kesesuaian kuis dengan durasi } \\ \text { waktu }\end{array} & 6 & 8 & 75 & \text { Baik } \\ \text { Tingkat kesulitan soal tiap level } & 12 & 16 & 75 & \text { Baik }\end{array}$

Rerata hasil dari validasi ahli materi terhadap gim kuis suplemen buku ajar pengantar dasar IPA sebesar 78,32\%. Gim kuis ditinjau dari segi materi dinyatakan valid berdasarkan rerata hasil validasi ahli materi lebih besar dari $61 \%$.

\section{c. Validasi praktisi}

Validasi desain gim kuis berbasis website suplemen buku ajar pengantar dasar IPA oleh praktisi dan juga oleh teman sejawat dirinci dalam tabel 3. Aspek yang dinilai oleh praktisi dan teman sejawat meliputi tampilan layout, penggunaan warna, penggunaan bahasa, navigasi tombol, tingkat kesulitan tiap level, kesesuaian soal dengan materi serta kemudahan akses. Berikut ringkasan hasil penilaian teman sejawat dan praktisi terhadap produk gim kuis.

Tabel 3. Rincian hasil penilaian praktisi dan teman sejawat

\begin{tabular}{llccccccc}
\hline No & Aspek & Prkts & Prkts & Prkts & Sjwt & Sjwt & Rerata & Keterangan \\
& Penilaian & $\mathbf{1}$ & $\mathbf{2}$ & $\mathbf{3}$ & $\mathbf{1}$ & $\mathbf{2}$ & & \\
\hline $\mathbf{1}$ & Tampilan & 83.5 & 82.4 & 84.2 & 82.7 & 83.3 & 83.22 & Sangat Baik \\
$\mathbf{2}$ & Warna & 84.3 & 85.6 & 83.3 & 82.6 & 83.4 & 83.84 & Sangat Baik \\
$\mathbf{3}$ & Bahasa & 74.6 & 72.3 & 75.7 & 74.6 & 76.4 & 74.72 & Baik \\
$\mathbf{4}$ & Navigasi & 78.8 & 76.9 & 74.5 & 77.2 & 76.8 & 76.84 & Baik \\
$\mathbf{5}$ & Kesulitan & 77.8 & 78.9 & 78.6 & 77.8 & 78.8 & 78.38 & Baik \\
$\mathbf{6}$ & Kesesuaian & 74.8 & 77.8 & 73.8 & 75.8 & 74.3 & 75.3 & Baik \\
$\mathbf{7}$ & Aksesibilitas & 80.2 & 82.6 & 82.3 & 82.4 & 84.4 & 82.38 & Sangat Baik \\
\hline
\end{tabular}

\section{Hasil tahap perbaikan desain}

Tahap ke lima dari pengembangan gim kuis berupa perbaikan desain berdasarkan hasil dari validator pada tahap sebelumnya. Perbaikan yang dilakukan berupa isi dari gim kuis sesuai saran dan masukan dari ahli media dan juga ahli materi. Dari penilaian oleh ahli media diperoleh masukan berupa tampilan gim dibuat lebih cerah, peletakan tombol lebih disesuaikan dengan posisi konten serta penggunaan warna lebih kontras. Masukan dari ahli materi berupa pembagian materi untuk setiap level menyesuaikan dengan cakupan materi pada buku ajar dan bukan berdasarkan jumlah level gim, penentuan durasi waktu disesuaikan dengan jumlah soal yang ditampilkan dalam setiap level dan tidak harus dibuat sama serta tingkat kesulitan level dibuat lebih sulit Ketika sudah menguasai beberapa materi pada buku ajar.

Berdasarkan masukan dari ahli media dan ahli materi, produk gim kuis hasil pada tahap sebelumnya dilakukan penyesuaian dengan mengacu pada apa yang disarankan oleh validator. Penyesuaian yang dilakukan diantaranya warna pada halaman awal gim kuis di buat lebih kontras sehingga teks dapat terbaca jelas, durasi untuk tiap level disesuaikan berdasarkan jumlah soal. Kesulitan soal untuk setiap kenaikan level dibuat lebih sulit dan lebih menantang.

\section{Hasil tahap uji coba desain}


Produk gim kuis suplemen buku ajar pengantar dasar IPA diujicobakan kepada mahasiswa PGSD Universitas Muhammadiyah Kotabumi dengan subjek uji coba sebanyak 35 mahasiswa. Uji coba dilakukan pada tanggal 11 September 2021. Setelah melakukan simulasi menggunakan gim kuis, mahasiswa diberikan angket untuk menilai gim kuis. Hasil uji coba produk diperoleh informasi berupa masukan dan saran dari hasil isian angket oleh mahasiswa. Berikut ringkasan beberapa masukan dan saran dari hasil dari uji coba produk disajikan pada tabel 4.

\section{Tabel 4. Saran dan masukan dari subjek uji coba produk}

\begin{tabular}{|c|c|}
\hline Aspek & Masukan dan Saran \\
\hline Tampilan game & Pada halaman pengerjaan kuis, tombol kirim jawaban tertutup susah di klik. \\
\hline kuis & $\begin{array}{l}\text { Diperbaiki Kembali agar mudah diklik saat ingin mengirim jawaban. } \\
\text { Tombol lihat hasil susah diakses, perlu diperbaiki }\end{array}$ \\
\hline Durasi waktu kuis & Durasi waktu ditambah lagi, te \\
\hline Informasi $l$ & Informasi pengguna hendaknya dita \\
\hline Ukuran huruf & $\begin{array}{l}\text { Ukuran huruf pada soal kuis ada beberapa yang tidak terbaca, diperbaiki } \\
\text { kembali }\end{array}$ \\
\hline Tombol pilihan & Tombol pilihan jawaban ada yang tidak bisa diklik, diperbaiki kembali \\
\hline
\end{tabular}

\section{Hasil tahap revisi desain}

Hasil tahap uji coba gim kuis diperoleh data kualitatif berupa saran dan masukan dari mahasiswa. Data tersebut dijadikan acuan dalam merevisi gim kuis tetapi tetap berpedoman pada hasil validasi ahli. Revisi gim kuis dilakukan pada informasi pengguna ditambahkan menu profil, pada tombol kirim jawaban kuis dan tombol lihat hasil, serta penyesuaian ukuran huruf pada soal kuis yang terlalu kecil dilakukan perbaiki dan penyesuaian. Durasi waktu untuk penyelesaian gim kuis tidak dilakukan perubahan karena salah satu tingkat kesulitan dari gim kuis terletak pada durasi waktu yang telah ditentukan.

\section{Hasil tahap uji coba pemakaian}

Setelah dilakukan revisi pada tahap sebelumnya, gim kuis suplemen buku ajar pengantar dasar IPA dilakukan uji coba pemakaian. Subjek uji coba pemakaian gim kuis adalah mahasiswa PGSD Universitas Muhammadiyah Kotabumi sebanyak 42 mahasiswa. uji coba pemakaian dilakukan untuk mengetahui kelayakan gim kuis baik dari tampilan maupun fungsinya. Berikut hasil dari uji coba pemakaian gim kuis suplemen buku ajar pengantar dasar IPA:

a. Data hasil belajar mahasiswa

Data hasil belajar diperoleh melalui pretest pada awal perkuliahan dan postest pada akhir perkuliahan. Penggunaan game kuis diberikan pada pertengahan perkuliahan sehingga efektivitas dari produk hasil pengembangan terlihat dari hasil preetest dan postest. Berikut rincian hasil preetest dan postest perkuliahan pengantar dasar IPA menggunakan suplemen bahan ajar berupa gim kuis disajikan pada tabel 5 sebagai beriktu.

\section{Tabel 5. Data hasil pretest dan postest}

\begin{tabular}{lll}
\hline Kriteria & Hasil Pretest & Hasil Postest \\
\hline Nilai Mak & 72 & 100 \\
Nilai Min & 53 & 67 \\
Rata-Rata & 62,5 & 83,5
\end{tabular}




$\begin{array}{lll}\text { Nilai KKM } & 75 & 75 \\ \text { Siswa yang tuntas } & 27 & 38 \\ \text { Siswa yang tidak tuntas } & 15 & 4\end{array}$

Perbandingan rerata nilai preetest dan postest mengalami kenaikan sebesar 33,6\% dan ketuntasan mahasiswa setelah belajar menggunakan game kuis sebesar $90,47 \%$. Hal ini menunjukkan penggunaan game kuis suplemen buku ajar pengantar dasar IPA efektif karena mahasiswa yang lulus lebih dari $80 \%$.

b. Data angket penilaian produk media pembelajaran

Tingkat kepraktisan penggunaan game kuis suplemen buku ajar pengantar dasar IPA diperoleh dari angket penilaian oleh subjek uji coba. Rincian hasil angket penilaian dari mahasiswa disajikan pada tabel 6 sebagai berikut.

Tabel 6. Hasil penilaian game kuis suplemen buku ajar pengantar dasar IPA berbasis website

\begin{tabular}{lcc}
\hline Aspek yang dinilai & $\begin{array}{c}\text { Persentase perolehan Nilai } \\
(\mathbf{\%})\end{array}$ & Kategori \\
\hline Dayatarik game kuis & 91.2 & Sangat Baik \\
Tingkat kesulitan tiap level & 87.6 & Sangat Baik \\
Manfaat game kuis & 82.4 & Sangat Baik \\
\hline \multicolumn{1}{c}{ Jumlah Rata-Rata } & $\mathbf{8 7 . 0 6}$ & Sangat Baik \\
\hline
\end{tabular}

Rerata uji kepraktisan gim kuis suplemen buku ajar pengantar dasar IPA lebih dari $61 \%$ yang berarti penggunaan gim kuis dalam pembelajaran pengantar dasar IPA dinyatakan praktis dan dapat dilanjutkan.

c. Saran dan masukan hasil uji coba pemakaian

Gim kuis suplemen buku ajar pengantar dasar IPA yang diujicobakan mendapat saran dan masukan dari subjek uji coba pemakaian. Berikut beberapa ringkasan saran dan masukan dari subjek uji coba pemakaian gim kuis disajikan pada tabel 7.

Tabel 7. Komentar, saran dan masukan hasil uji coba pemakaian

\begin{tabular}{ll}
\hline \multicolumn{1}{c}{ Aspek } & \multicolumn{1}{c}{ Masukan dan Saran } \\
\hline $\begin{array}{l}\text { Tampilan game } \\
\text { kuis }\end{array}$ & $\begin{array}{l}\text { Game kuis terlihat keren, pada halaman profil tidak diberikan akses ganti } \\
\text { email. Sarannya diberikan akses untuk mengubah email agar lebih mudah } \\
\text { digunakan } \\
\text { Game kuis sangat menantang, semakin lama dan tinggi levelnya } \\
\text { waktunya semakin berkurang. Sarannya waktunya ditambah agar tidak } \\
\text { terburu-buru dalam mengerjakan soal. }\end{array}$ \\
$\begin{array}{l}\text { Ukuran huruf } \\
\text { Tombol pilihan }\end{array}$ & $\begin{array}{l}\text { Tombol pilihan terkadang tidak muncul, diperbaiki lagi agar mudah } \\
\text { diakses. }\end{array}$ \\
\hline
\end{tabular}

\section{Hasil tahap revisi produk}

Masukan dan saran pada tahap uji coba pemakaian digunakan sebagai referensi untuk menyempurnakan gim kuis berbasis website suplemen buku ajar pengantar dasar IPA sebagai produk akhir hasil pengembangan. Gim kuis suplemen 
buku ajar pengantar dasar IPA dapat diakses menggunakan ponsel pintar menggunakan aplikasi google chrome atau web browser lain dengan mengakses melalui link http://rohmani.web.id. Beberapa perbaikan yang dilakukan yaitu optimalisasi beberapa fitur dari gim kuis seperti tombol dan juga tampilan dari gim kuis sesuai masukan subjek uji coba pemakaian.

Berdasarkan data hasil uji coba pemakaian produk, penggunaan suplemen buku ajar pengantar dasar IPA berupa gim kuis berbasis website mampu meningkatkan hasil belajar mahasiswa. Hal ini memperkuat hasil penelitian (Broussard, 2014; Meishar-Tal \& Kesler, 2021; Oprins et al., 2015) bahwa pembelajaran menggunakan game memberikan dampak positif diberbagai aspek pada diri peserta didik. Gim kuis berbasis website sebagai suplemen buku ajar pengantar dasar IPA menjadi prototipe untuk pengembangan suplemen buku ajar yang lainnya.

\section{SIMPULAN}

Suplemen buku ajar pengantar dasar IPA berupa gim kuis berbasis website dapat dikembangkan dengan menggunakan tahapan yang dikemukakan oleh Sugiyono dan dapat diakses menggunakan ponsel pintar mahasiswa. Tingkat kelayakan gim kuis di uji dengan menghitung tingkat validasi ahli media dan ahli materi. Efektivitas game kuis suplemen buku ajar pengantar dasar IPA sebesar 90,47\% dan dinyatakan efektif karena lebih besar dari $80 \%$. Gim kuis praktis digunakan dalam perkuliahan pengantar dasar IPA sebagai suplemen buku ajar karena hasil uji kepraktisan sebesar $87,06 \%$ yang berarti bahwa gim kuis dinyatakan praktis Ketika digunakan dalam pembelajaran. Penggunaan gim kuis sebagai suplemen buku ajar pengantar dasar IPA dapat meningkatkan hasil belajar mahasiswa yang artinya penggunaan ponsel pintar dalam pembelajaran mampu mengurangi dampak negatif serta memaksimalkan manfaat dari penggunaan ponsel pintar.

\section{DAFTAR PUSTAKA}

Abildinovaa, G. M., Alzhanova, A. K., Ospanovab, N. N., Taybaldievac, Z., Baigojanovaa, D. S., \& Pashovkina, N. O. (2016). Developing a mobile application "educational process remote management system" on the android operating system. International Journal of Environmental and Science Education, 11(12), 5128-5145. http://www.ijese.net/makale/692.html

Al-Qaysi, N., Mohamad-Nordin, N., \& Al-Emran, M. (2020). Employing the technology acceptance model in social media: A systematic review. In Education and Information Technologies (Vol. 25, Issue 6). Education and Information Technologies. https://doi.org/10.1007/s10639-020-10197-1

Alfiras, M., \& Bojiah, J. (2020). Printed Textbooks Versus Electronic Textbooks: A Study on the Preference of Students of Gulf University in Kingdom of Bahrain. International Journal of Emerging Technologies in Learning, 15(18), 40-52. https://doi.org/10.3991/ijet.v15i18.15217

Awwaabiin, S. (2020). Pengertian PHP, Fungsi dan Sintaks Dasarnya. Niagahoster Blog. https://www.niagahoster.co.id/blog/pengertianphp/\#: :text=PHP (PHP\%3A Hypertext Preprocessor), berbeda tergantung 
data yang diproses.

Bierman, P., Massey, C., \& Manduca, C. (2006). Reconsidering the textbook. Eos Science News by AGU, 87(31), 306. https://doi.org/10.1029/2006eo310004

Broussard, M. J. S. (2014). Using games to make formative assessment fun in the academic library. Journal of Academic Librarianship, 40(1), 35-42. https://doi.org/10.1016/j.acalib.2012.12.001

Csibi, S., Griffiths, M. D., Demetrovics, Z., \& Szabo, A. (2019). Analysis of Problematic Smartphone Use Across Different Age Groups within the 'Components Model of Addiction.' International Journal of Mental Health and Addiction, 616-631. https://doi.org/10.1007/s11469-019-00095-0

Gorbanev, I., Agudelo-Londoño, S., González, R. A., Cortes, A., Pomares, A., Delgadillo, V., Yepes, F. J., \& Muñoz, Ó. (2018). A systematic review of serious games in medical education: quality of evidence and pedagogical strategy. Medical Education Online, 23(1). https://doi.org/10.1080/10872981.2018.1438718

Hermawan, D., Haryanto, I. P. B., \& Yogis, I. G. D. M. (2019). Pemanfaatan Smartphone sebagai Media Informasi untuk Meminimalisir Dampak Negatif Globalisasi. Jurnal Widyabhakti, 1(3), 113-120. http://widyabhakti.stikombali.ac.id/index.php/widyabhakti/article/view/116

Horsley, M., Knight, B., \& Huntly, H. (2010). The Role of Textbooks and Other Teaching and Learning Resources in Higher Education in Australia: Change and Continuity in Supporting Learning. IARTEM E-Journal, 3(2), 43-61. https://doi.org/https://doi.org/10.21344/iartem.v3i2.787

John, D. (2020). Coronavirus (COVID-19) and Online Learning in Higher Institutions ofEducation: A Survey of the Perceptions of Ghanaian International Students in China. Online Journal of Communication and Media Technologies, 10(3), 0-9. https://www.ojcmt.net/download/coronaviruscovid-19-and-online-learning-in-higher-institutions-of-education-a-surveyof-the-8286.pdf

Kapralos, B., Fisher, S., Clarkson, J., \& van Oostveen, R. (2015). A course on serious game design and development using an online problem-based learning approach. Interactive Technology and Smart Education, 12(2), 116-136. https://doi.org/10.1108/ITSE-10-2014-0033

Knight, B. A. (2015). Teachers' use of textbooks in the digital age. Cogent Education, 2(1), 1-10. https://doi.org/10.1080/2331186X.2015.1015812

Kominfo. (2017). Survey Penggunaan TIK 2017 Serta Implikasinya terhadap Aspek Sosial Budaya Masyarakat. Kementrian Komunikasi dan Informatika Republik Indonesia. https://www.indonesiabaik.id/index.php/ebook/surveypenggunaan-tik-2017 
Magoc, D. (2011). Using the Web to Increase Physical Activity in College Students. American Journal of Health Behavior, 35(2), 142-154. https://doi.org/10.5993/AJHB.35.2.2

Mascita, D. E. (2021). Mendesain Bahan Ajar Cetak Dan Digital. CV.Media Sains Indonesia.

McKenna, H. (2019). Emergent Digital Literacies (pp. 133-159). https://doi.org/10.4018/978-1-5225-7882-6.ch005

Meishar-Tal, H., \& Kesler, A. (2021). "If I create a game I'll learn": online game creation as a tool to promote learning skills of students with learning difficulties. Interactive Learning Environments, $O(0)$, 1-12. https://doi.org/10.1080/10494820.2021.1919146

Oprins, E., Visschedijk, G., Windesheim, H., \& Schuit, S. C. E. (2015). The gamebased learning evaluation model ( GEM ): measuring the effectiveness of serious games using a standardised method Maartje Bakhuys Roozeboom Mary Dankbaar Wim Trooster. 7(4), 326-345. https://doi.org/10.1504/IJTEL.2015.074189

Philpot, T. A., Hall, R. H., Hubing, N., \& Flori, R. E. (2005). Using games to teach statics calculation procedures: Application and assessment. Computer Applications in Engineering Education, 13(3), 222-232. https://doi.org/10.1002/cae.20043

Pusparisa, Y. (2021). Daftar Negara Pengguna Smartphone Terbanyak, Indonesia Urutan Berapa? Databoks. https://databoks.katadata.co.id/datapublish/2021/07/01/daftar-negarapengguna-smartphone-terbanyak-indonesia-urutan-berapa

Rahman, T., Amalia, A., \& Aziz, Z. (2021). From Digital Literacy to Digital Intelligence A Comparative Study of Digital Literacy Frameworks. Atlantis Press, 518(ICoSIHESS 2020), 154-159. https://doi.org/https://doi.org/10.2991/assehr.k.210120.119

Rao, S. S. (2005). Electronic books: Their integration into library and information centers. Electronic Library, 23(1), 116-140. https://doi.org/10.1108/02640470510582790

Raymond, R. (2012). Determinans of the Quality of Primary and Secondary Publick Education in West Virginia. Encyclopedia of Law and Higher Education, 3(4), 450-470. https://doi.org/10.4135/9781412969024.n17

Riduwan. (2011). Dasar-Dasar Statistik. Alfabeta.

Salmy, J. Q., Aryanto, H., \& Christianna, A. (2018). Perancangan Board Game Mengenai Baik Buruknya Penggunaan Smartphone Bagi Remaja. Jurnal DKV Adiwarna, 1-9. http://publication.petra.ac.id/index.php/dkv/article/view/7519

Stone, R. W., \& Baker-Eveleth, L. J. (2013). Students' intentions to purchase 
electronic textbooks. Journal of Computing in Higher Education, 25(1), 2747. https://doi.org/10.1007/s12528-013-9065-7

Sugiyono. (2016). Metode Penelitian Kuantitatif, Kualitatif dan R\&D. Alfa Beta.

Sun, J., Flores, J., \& Tanguma, J. (2012). E-textbooks and students' learning experiences. Decision Sciences Journal of Innovative Education, 10(1), 6377. https://doi.org/10.1111/j.1540-4609.2011.00329.x

Traverso, A., Parmigiani, D., \& Pennazio, V. (2014). Mobile devices and development of learning strategies. ATEE Annual Conference "Transitions in Teacher Education and Professional Identities," August, 69-80. https://www.researchgate.net/publication/282326481_Mobile_devices_and_ development_of_learning_strategies

Utami, A. N. (2019). Dampak Negatif Adiksi Penggunaan Smartphone Terhadap Aspek-Aspek Akademik Personal Remaja. Perspektif Ilmu Pendidikan, 33(1), 1-14. https://doi.org/10.21009/PIP.331.1

Van Boxtel, C., Van der Linden, J., \& Kanselaar, G. (2000). The use of textbooks as a tool during collaborative physics learning. Journal of Experimental Education, 69(1), 57-76. https://doi.org/10.1080/00220970009600649

Wang, T. H. (2008). Web-based quiz-game-like formative assessment: Development and evaluation. Computers and Education, 51(3), 1247-1263. https://doi.org/10.1016/j.compedu.2007.11.011 